\title{
Are scientific capacities and industrial funding critical for universities' knowledge- transfer activities? - A case study of South Korea
}

\author{
Ki-Seok Kwon*
}

This study focuses on the knowledge-transfer activities of Korean universities at the organisational level. Considering the idiosyncratic characteristics of the Korean university system, as well as those of universities in other recently developed Asian countries experienced a rapid economic catch-up, this study is more interested in the relationship between the scientific capacity of universities and their knowledge-transfer activities, and between universities' funding sources and their knowledge-transfer activities. According to the results of the study, scientific capacity in a specific discipline, such as engineering, is important for universities in both other developed countries and in Korea, while scientific capacity (regardless of the discipline) is apparently not important for Korean universities, particularly in the area of domestic publication. Furthermore, this result supports the proposition suggested that strategically chosen industrial sectors in rapid catch-up countries are closely related to the scientific capacity of universities in specific disciplines. In terms of funding sources, the amount of funding from industry is strongly related to the knowledge-transfer activities of universities, whereas the proportion of funding from industry relative to the total amount of funding is not as significantly related to knowledge-transfer activities. The failure to identify a significant relationship between central government funding and knowledge-transfer activities may be due to less strict requirements for commercialisation in central government R\&D programmes. Otherwise, central government funding fails to generate meaningful knowledge-transfer activities in universities.

\section{Introduction}

The importance of the exploitation of academic knowledge has grown over the last few decades. As a result, thorough research on the effective conditions of universityindustry linkages has been carried out (e.g. Nelson (1986), Mansfield (1991, 1998)). In contrast, aside from some papers exploring systemic characteristics in relation to the national innovation system (e.g. Intarakumnerd (2002), Wong et al. (2007)), these issues have rarely been studied in developing or rapid catch-up countries, compared to studies that have been carried out in industrialised countries (Eun et al. 2006). In particular, the national innovation system experienced a rapid catch-up such as South Korea has idiosyncratic characteristics different both from developing and developed countries. For example, some South Korean companies (e.g. Samsung) have been already recognised as a global leader in several fields of technological innovation since the 1990 s. However, the quality of Korean universities' research is still lagging behind that of universities in developed countries in spite of the government's recent stresses on

\footnotetext{
* Korean Educational Development Institute (KEDI), Seoul, South Korea.
} 
academic excellence (Lee 2009, MEST 2008, Lee and Kwun 2003). Therefore, current Korean national innovation system aims creative knowledge to create a new technological path rather than to follow the path given by developed countries. In this vein, the Korean national innovation system are characterised as a post catch-up country, which is located between catch-up and developed countries (Seung and Kim 2010, Song and Hwang 2006).

The universities in the Asian countries, which have achieved a rapid economic catch-up or have arrived at a post catch-up stage (e.g. South Korea, Taiwan, and Singapore), have some unique characteristics due to their relationship with the government. Firstly, the development of universities' academic research in those countries tends to be encouraged by governments in order to support their industry. Many studies have focused on universities in developed countries, which have sufficient academic potential to carry out cutting-edge research, as well as exploring its commercial application. In contrast, existing empirical literature addressing the influence of scientific capacity as well as other factors on the knowledge-transfer performance of universities in the context of rapid catch-up and developing countries is quite rare, aside from studies taking a preliminary (in terms of the number of explanatory variables) approach (e.g. Albuquerque (2001)), or giving a brief overview of the role of public research institutions in the rapid economic catch-up process (e.g. Mazzolini \& Nelson (2007)). Secondly, during the last half century, universities in recently developed Asian countries, which have experienced rapid economic catch-up, have been strongly influenced by governmental higher education policy (Cummings 1997). Recently in those countries, governments have initiated various programmes, which encourage the economic contribution of academia to local economies (Hershberg et al. 2007). In this regard, government can be regarded as a critical resource provider influencing knowledge-transfer activities of universities.

Against this backdrop, this study focuses on the relationship between academic research and knowledge-transfer activities, and between funding sources and knowledge-transfer activities of Korean universities at the organisational level. In particular, not only the characteristics of research output, such as academic publication and knowledge-transfer performance including patenting and technology-transfer activities, but also the relationships between the former and the latter are explored. More specifically, according to scientific capacity and research funding, differentiated characteristics of knowledge-transfer performance are addressed.

The main research question addressed in this paper is what are the relationships between scientific research and knowledge-transfer activities, and between funding sources and knowledge-transfer activities of Korean universities? In order to answer this question, more specific questions need to be asked:

- What characteristics are observed in the outputs of the universities' activities at the organisational level?

- To what extent are the scientific capacity and funding sources of universities related to knowledge-transfer activities at the organisational level?

This paper is structured as follows. Section 2 provides a literature review of the university factors influencing knowledge-transfer performance at the organisational level. It then suggests a hypothesis for the relation of scientific capacity and sources of funding to knowledge-transfer activities. Section 3 introduces the methodology of the sample used in this study, and a statistical model that consists of dependent and independent 
variables. Section 4 discusses the statistical results. Finally, based on these results, Section 5 presents the conclusion.

\section{Determinants of knowledge-transfer activities of universities}

\subsection{Scientific capacity and knowledge-transfer activities ${ }^{1}$ of universities}

In this subsection, we focus on the effect of academic research on knowledge-transfer activities of universities at the organisational level. Even though the direction of causality needs to be carefully considered, this can be rephrased as an issue addressing the relationship between academic research (i.e. the second mission), and industrial collaboration (i.e. the third mission) activities of universities at the organisational level. Regarding this issue, existing literature can be divided into two somewhat contradictory camps.

Some studies suggest a negative relationship between the second and third missions of universities. For example, the empirical results of a survey carried out by Rahm and Morgan show that the applied orientation of academic research is positively related to the intensity of collaboration with companies (cited in Florida and Cohen 1999). Moreover, the quality of universities' academic output has a negative effect on the propensity of their academics to interact with the private sector (Ponomariov 2008). However, this proposition cannot be applied to all kinds of universities. Brooks and Randazzese (1999) mention that academics in relatively few prestigious institutions are unlikely to be vulnerable to short-term industrial needs. In a similar vein, Geuna (1997) shows that a large proportion of UK universities are involved in short-term and less basic research contracts from industry, while a few prestigious universities enjoy longterm and more basic research contracts.

In contrast, studies refuting this negative relationship between academic research (or scientific excellence) and various knowledge-transfer activities (e.g. patenting and incubating activities) have also emerged. Based on 18 years of panel data from 89 US universities, Owen-Smith (2003) maintains that a newly emerged 'hybrid regime' encourages universities with a better scientific reputation (as measured by publication impact) to patent more and vice versa. In a similar vein, analysing the outputs and characteristics of UK universities and affiliated academics, Ambos et al. (2007) hold that the conflict between academic and commercial orientation can be harmonised through the establishment of a dual structure at the university or department level. Sapsalis et al. (2006) hold the view that scientific capacity is essential for industrial collaboration. In the case of 87 European universities, publication activity at the organisational level has been shown to have a statistically significant and positive relationship to patenting activities. Moreover, investigating the spin-off rate of 101 US universities, Di Gregorio and Shane (2003) maintain that universities with higher intellectual eminence can more easily create start-ups. Similarly, universities with highly-rated departments in science and engineering are also heavily involved in spin-off activity (O'Shea et al. 2005).

However, as far as we can tell, literature directly investigating this issue (particularly at the organisational level) in the context of developing countries, is rare. Furthermore, the debate between the two contrasting views outlined above cannot be directly applicable to universities in developing countries. This is because the scientific capacity of the higher education system in those countries is generally not strong enough to be fully exploited for economic contribution. Accordingly, other factors (such 
as sources of funding and institutional characteristics) may be more important than scientific capacity. Furthermore, the contribution of scientific capacity of developing countries' universities could be channelled through different routes. As De Campos (2009) mentions, the channels of economic contribution of universities in developing regions (e.g. teaching and informal consultancy) may be different from those in industrialised regions (e.g. formal long-term research contracts).

\subsection{Funding structure and knowledge-transfer activities of universities}

Griliches and his colleagues have applied econometric models to the relationship between academic patenting and R\&D expenditure using a patent production function (Adams \& Griliches 1996; Griliches 1990). Regarding the employment of this model, the following studies are in a similar vein to that of these scholars. Mansfield (1998) suggests that the size of US universities' R\&D expenditure has a positive relationship to the universities' contribution to industry. This is supported by the empirical finding that annual university-wide $R \& D$ expenditure has a significant, positive relationship to spinoff activity (Carlsson \& Fridh 2003; Powers \& McDougall 2005). Furthermore, in the case of US universities, Coupé (2003) finds not only a significant, positive effect of academic R\&D expenditure, but also decreasing returns on patenting activities at the university level. In particular, this subsection reviews existing literature on the influence of structural characteristics (particularly funding sources) of academic R\&D expenditure on a university's knowledge-transfer activities. Furthermore, some methodological problems of the existing studies and their implications in the context of developing countries are discussed.

Intuitively, funding from industry seems more likely to encourage universities to produce commercially-oriented knowledge for industry and transfer it when compared to funding from other sources, such as governments. Regarding this, Di Gregorio and Shane (2003) suggest three possible explanations for why industry funding is positively related to universities' knowledge-transfer activities. Firstly, industry is more likely to invest in potentially commercial research than government. Secondly, industry is more likely to fund low-risk research than government. Thirdly, government-funded research is more likely to face information asymmetry problems than industry-funded research, so the former is less likely to be financed by entrepreneurs than the latter.

Empirically, Powers (2003) supports the above proposition based on the finding that the size of industrial funding has a significant, positive relationship to patent production within universities. Di Gregorio and Shane (2003) find that universities with higher amounts of industry funding create a significantly higher number of spin-offs. Conversely, universities with a strong attitude towards research focusing on commercial research for industry are more likely than other universities to attract funding from industry (Rosenberg \& Nelson 1994).

However, certain other empirical studies provide rather different evidence that is inconsistent with the empirical findings supporting a positive relationship between the amount of industrial funding and the knowledge-transfer activities of universities. Foltz et al. (2000) show that industrial and internal funding have no significant effect on universities' patenting activities, while federal and state funding have a significant, positive effect on them. Payne and Siow (2003) also find that federal funding is significantly and positively related to the patent production of universities. However, in contrast to their results from previous a study in 2000, Foltz et al. (2001) find that internal funding and state funding are positively and significantly related to patenting activities in the field of 
agricultural biotechnology, while industrial and federal funding are not. In a similar vein, Powers (2004) also confirms that industrial R\&D support is not significantly related to university technology transfer. Furthermore, when considering not only the absolute amount of funding, but also the proportion of certain sources of funding relative to the total, the empirical findings from existing studies appear to be more complicated. Henderson et al. (1998) suggest that the proportion of industrial funding is related to application-oriented academic research. O'Shea et al. (2005) find that the proportion of industrial funding has a significant, positive impact on the establishment of university spin-off firms. However, Di Gregorio and Shane (2003) find that the proportion of industrial funding is not significantly related to universities' creation of spin-offs, while the absolute size of industrial funding is significantly related to the creation of such spin-offs.

This inconsistency may be due to several methodological reasons. Firstly, the contradictory statistical findings described above could be the result of different sampling methods. The characteristics of the university samples selected, as well as the population adopted, vary from study to study. For example, both Foltz et al. (2001) and Foltz et al. (2000) are interested in agricultural biotechnology patents. However, the former's research is based on cross-sectional data of 142 US universities from the US patent office database, while the latter's research is based on eight years of panel data for 127 US universities from the AUTM (Association of University Technology Managers) survey. The research of both Powers (2004) and Powers (2003) is based on annual licensing surveys of the AUTM. However, the universities in the older study comprise 108 US Research I and II institutions based on the Carnegie (1994) classification, while those in Powers (2004) are 104 US doctoral-intensive and extensive institutions categorised as the two new top tiers of the Carnegie classification. Furthermore, the study of Payne and Siow (2003) includes 223 US higher institutions categorised as research or doctoral universities based on the Carnegie (1994) classification, while Di Gregorio and Shane (2003) selected 116 US universities with two or more years of TTO data available from AUTM.

Secondly, as is clear above, most of the research discussed here has been carried out mainly on US universities rather than European and Japanese universities, except for a few recent studies such as Ljunngberg et al. (2007) on a Swedish university, and Ambos et al. (2007) on UK universities. Moreover, it is currently very hard to find studies that consider the context of developing countries, with the exception of some recent studies about strengthening university-industry linkages in developing countries. Therefore, in order to extend the application of existing findings to other countries (or other regions), research on the relationship between industrial funding and knowledgetransfer outputs in developing countries may contribute to filling both an empirical and theoretical gap with respect to existing studies.

Finally, with regard to a possible reason for the inconsistent statistical results given above, Carayol (2007) asserts that the university level is not appropriate for investigating the relationship between industrial funding and the knowledge-transfer activities of a university. To this end, he suggests a change of the unit of analysis from the university to the laboratory level. However, this is not the only solution. Through a suitable classification of universities, we can obtain a more homogeneous subgroup for our sample. Moreover, this classification can be included in statistical models as one of the control variables, so we can manage the heterogeneity of the various types of universities selected in the sample. 
As detailed above, the empirical results of the influence of industrial funding, both in terms of both absolute amount and proportion, on academic patenting at the university level are inconsistent. Accordingly, we may conclude that the evidence on the relationship between sources of funding and knowledge-transfer activities is inconclusive (De Campos 2006).

\subsection{Hypotheses}

If we consider the systemic characteristics of Korean universities, the implications from the review of the existing literature, and the preliminary findings, certain hypotheses regarding the relationship between characteristics of universities and their knowledgetransfer activities can be put forward.

Firstly, the scientific capacity of universities in a rapid catch-up country such as Korea has been strengthened very recently. In the 1990s, the most successful programmes to support academic research were SRCs (Science Research Centres), ERCs (Engineering Research Centres) and RRCs (Regional Research Centres) created in universities by KOSEF and MOST (the Ministry of Science and Technology). According to Hwang and Yoon (2003), 5\% of all Korean academics in science and engineering joined SRC and ERC programmes, and produced $26.4 \%$ of all Korean SCI papers between 1990 and 1997. This change was possible due to the government's strong support for several strategic areas of research (e.g. IT and BT) through various national R\&D programmes (Song 2002). Moreover, Yun and Ahn (2002) find the disciplinary specialisation of SCI publications (particularly in engineering) in Korea and Taiwan is very high compared to those in developed Western countries. In this regard, academic research at universities tends to be encouraged in particular areas that are easily exploited commercially. In other words, the scientific capacity of individual universities can be regarded as being closely related to their knowledge-transfer activities. Based on the above argument, the following hypothesis can be suggested.

Hypothesis 1: Universities with a stronger scientific capacity in certain disciplines are likely to show a higher level of knowledge-transfer activities.

However, scientific capacity in terms of publications can be measured in a variety of ways, including number of domestic publications, number of SCI publications and number of publications in a certain area of research. Firstly, among the newly industrialising countries in Asia, Korean academic society would seem to have the academic system most significantly based both on indigenous language (i.e. Korean) and on English (Altbach 1989). Accordingly, in measuring scientific capacity, we cannot exclude the number of domestic publications. However, as is frequently observed in interviews with Korean academics, the number of SCI publications is regarded as a more reliable measure in terms of a certain level of quality, due to the stricter review process. Moreover, considering the close relationship between the discipline of engineering and its industrial contribution in Korea, scientific capacity can be measured by the number of publications in the field of engineering. As a result, by applying various definitions of scientific capacity in the above hypothesis, the relationship between different types of scientific capacity and knowledge-transfer activities can be explored.

Secondly, during the last decade, Korean universities' direct industrial contribution has been strongly encouraged by central government (Park et al., 2007). In particular, in terms of R\&D expenditure, Korean universities have become more dependent on 
central government funding than on other sources, particularly since the late 1990s (Bak, 2006). For example, the level of funding for university-industry cooperation programmes comprises $25 \%$ (1.8124 trillion won) of all national R\&D projects $(7.2283$ trillion won) in 2006 (Sohn et al., 2006). Furthermore, the recent increase in total expenditure is mostly due to the increase in central government funding (see Table 1). Therefore, the major increase in knowledge-transfer activities of Korean universities is likely to be influenced by the significant increase in central government funding. The various policy measures initiated by the central government in the 2000s support this argument. Based on the above, we propose a hypothesis focusing on the positive relationship between the amount of central government funding received by universities and their knowledge-transfer activities.

Hypothesis 2a: The universities with larger amounts of research funding from central government are likely to do participate more strongly in knowledge-transfer activities.

However, the small amount of funding from other sources, such as industry, does not necessarily mean that the sources of funding are independent from universities' knowledge-transfer activities. Accordingly, not only the effect of central government funding, but also that of other funding sources needs to be investigated in the empirical analysis later on in this paper. In particular, industrial funding may be a weaker predictor for universities' knowledge-transfer activities than central government funding, if we consider the government's strong financial contribution to universities' research expenditure.

As introduced in the literature review, the question of whether not only the absolute size of research funding, but also the proportion of research funding in relation to the total amount of funding, is an important factor for knowledge-transfer activities is an undetermined issue that needs more empirical investigation. Empirically, in Korea, according to different types of universities, the proportion of funding from each source is very different, while the amount of funding is quite similar. For example, the amounts of central government funding received by large public regional universities, large private regional universities and medium-sized and small private universities in Seoul are similar, whereas the proportions of central government funding of these three types of universities are quite different (Kwon, 2009a). These proportions of research funding could be closely related to not only research and teaching activities, but also knowledgetransfer activities. Moreover, as discussed in the formulation of Hypothesis 2a, central government funding is critical for universities' research and knowledge-transfer activities. Accordingly, if we consider the important role of central government funding in Korean universities' research activities, the proportion of central government funding could also be significantly related to knowledge-transfer activities. In this vein, an additional hypothesis focusing on this issue can be stated as follows.

Hypothesis $2 b$ : The proportion of universities' research funding from central government relative to the total amount of research funding positively affects the knowledgetransfer outputs of universities.

Finally, other factors influencing the relationship between research and knowledgetransfer activities (e.g. institutional characteristics, entrepreneurial orientation and environmental condition) are also included as control variables in our statistical model. In this way, considering the various characteristics of Korean universities, their activities, 
and their relationships, the influence of the other variables excluded in the above hypotheses is investigated according to the empirical results in the following analysis.

Table 1: Descriptive statistics of 145 Korean universities engaged in science and engineering

\begin{tabular}{|c|c|c|c|c|}
\hline & Mean & S.D. & Min & Max \\
\hline Years since foundation & 47.48 & 28.77 & 3 & 151 \\
\hline Legal status $(\mathrm{Pub}=1 / \mathrm{Pvt}=0)$ & .23 & .42 & 0 & 1 \\
\hline $\begin{array}{l}\text { Size (no. of academics in S\&E) } \\
\text { - Natural Science } \\
\text { - Engineering } \\
\text { - Medical \& Pharmaceutical } \\
\text { - Agriculture and Maritime }\end{array}$ & $\begin{array}{l}182.77 \\
38.15 \\
83.14 \\
52.01 \\
9.47\end{array}$ & $\begin{array}{l}190.56 \\
41.35 \\
67.02 \\
100.89 \\
16.99\end{array}$ & $\begin{array}{l}13 \\
0 \\
4 \\
0 \\
0\end{array}$ & $\begin{array}{l}987 \\
215 \\
287 \\
580 \\
98\end{array}$ \\
\hline $\begin{array}{l}\text { Teaching (no. of students) } \\
\text { - undergraduate } \\
\text { - postgraduate }\end{array}$ & $\begin{array}{l}4261.58 \\
890.92\end{array}$ & $\begin{array}{l}3327.36 \\
1462.26\end{array}$ & $\begin{array}{l}0 \\
0\end{array}$ & $\begin{array}{l}13545 \\
9946\end{array}$ \\
\hline Location (in Seoul $=1 / \mathrm{No}=0$ ) & .20 & .40 & 0 & 1 \\
\hline $\begin{array}{l}\text { Number of papers published } \\
\text { - Domestic journals } \\
\text { - SCI journals } \\
\text { - Natural science discipline } \\
\text { - Engineering discipline }\end{array}$ & $\begin{array}{l}109.65 \\
125.68 \\
49.07 \\
121.18\end{array}$ & $\begin{array}{l}129.90 \\
320.18 \\
94.14 \\
200.15\end{array}$ & $\begin{array}{l}0 \\
0 \\
0 \\
0\end{array}$ & $\begin{array}{l}672.06 \\
3078.57 \\
859.77 \\
1240.66\end{array}$ \\
\hline $\begin{array}{l}\text { Amount of R\&D exp. by sources* } \\
\text { - Central gov’t } \\
\text { - Local gov’t } \\
\text { - Industry } \\
\text { - Overseas } \\
\text { - Self }\end{array}$ & $\begin{array}{l}113.70 \\
6.81 \\
24.23 \\
.35 \\
6.21\end{array}$ & $\begin{array}{l}232.47 \\
13.85 \\
49.34 \\
1.58 \\
11.87\end{array}$ & $\begin{array}{l}0 \\
0 \\
0 \\
0 \\
0\end{array}$ & $\begin{array}{l}1956.04 \\
102.57 \\
339.17 \\
14.97 \\
70.13\end{array}$ \\
\hline $\begin{array}{l}\text { Ratio of R\&D exp. by sources* } \\
\text { - Central gov't } \\
\text { - Local gov’t } \\
\text { - Industry } \\
\text { - Overseas } \\
\text { - Self }\end{array}$ & $\begin{array}{l}.66 \\
.08 \\
.20 \\
.001 \\
.07\end{array}$ & $\begin{array}{l}.22 \\
.13 \\
.17 \\
.005 \\
.14\end{array}$ & $\begin{array}{l}0 \\
0 \\
0 \\
0 \\
0\end{array}$ & $\begin{array}{l}1.0 \\
.86 \\
.88 \\
.06 \\
1.0\end{array}$ \\
\hline TTO size (no. of staff) & 15.08 & 14.65 & 0 & 78 \\
\hline Regional BERD* & 25101.65 & 32680.48 & 197.99 & $1.03 e+5$ \\
\hline $\begin{array}{l}\text { Patent applications } \\
\text { - Domestic } \\
\text { - Overseas }\end{array}$ & $\begin{array}{l}28.84 \\
4.80\end{array}$ & $\begin{array}{l}63.27 \\
18.46\end{array}$ & $\begin{array}{l}0 \\
0\end{array}$ & $\begin{array}{l}410 \\
174\end{array}$ \\
\hline Technology Transfer $^{+}$ & 3.89 & 7.36 & 0 & 40 \\
\hline Revenue from TT* & .61 & 1.66 & 0 & 13.62 \\
\hline
\end{tabular}

*unit: 0.1 billion won (US\$0.1 million in 2006).

${ }^{+}$Transfer of ownership regarding intellectual property rights (IPR) created by universities. 


\section{Methodology and Hypothesis}

\subsection{Data and Variables}

The data set has been mainly compiled from the KRF (Korea Research Foundation) annual survey on the academic research and knowledge-transfer activities of Korean universities in 2006. The data set contains input and output variables of the individual universities' activities, such as the number of academic staff, the amount of research funds from different sources, the number of internal research institutes and their research expenditure, and the number of papers, books, patents, technology transfers and research projects. In addition to this data set, the website of the Korea National Center for Education Statistics \& Information provides the number of undergraduate and postgraduate students in Korean universities.

The descriptive statistics shown in Table 1 provide us with institutional and environmental properties of Korean universities engaged in science and engineering. ${ }^{2}$ The average years since foundation (i.e. institutional maturity or age) of Korean universities is 47 , which is due to the enormous increase in the establishment of universities after the liberation in 1945 . About $77 \%$ of these institutions are private universities. The average university size as measured by the number of academics engaged in science and engineering is 183. The average TTO size as measured by the number of staff is 15 (this number is quite large because TTO personnel in Korean universities are involved not only in the business of knowledge-transfer but also in the management of externallyfunded R\&D programmes), and the distribution skews highly. In terms of region, $20 \%$ of universities are located in Seoul. The human and financial resources of the universities are also presented in Table 1 . More than $45 \%$ of academics in science and engineering are engaged in engineering, and most (75\%) of the research expenditure is funded by the central government.

Moreover, the characteristics of the universities' three main activities, teaching, research and knowledge transfer, can also be explored based on the descriptive statistics. Firstly, in terms of teaching, the average Korean university engaged in science and engineering has 4,262 undergraduates (i.e. 23 per academic) and 891 postgraduates (4.87 per academic). Secondly, in terms of research, Korean universities produce 110 papers in domestic journals and 126 papers in SCI journals per year. Moreover, funding from central government consists of more than $75 \%$ of the R\&D expenditure of Korean universities. Thirdly, in terms of knowledge-transfer activities, 29 domestic patents and five overseas patents were applied for in 2006, and 61 million Korean won (US\$61,000 in 2006) was earned by three technology transfers on average by Korean universities engaged in science and engineering.

\subsection{Model specification}

As introduced in 2.2, an economic model using a patent production function as a dependent variable is adopted here. The dependent variables are related to universities' knowledge-transfer activities in 2006 (i.e. the number of domestic and overseas patents applied for, the number of technology transfers and the revenue from the technology transfers). In terms of the independent variables and the control variables, the following factors influencing knowledge-transfer activities are employed: scientific capacity, funding sources of universities, institutional characteristics (e.g. size, age and legal 
status), size of TTOs (personnel or budget), regional business expenditure of R\&D, and properties of the universities (e.g. size, location, research expenditure). Alternatively, instead of institutional characteristics, dummy variables representing the universities' characteristics are adopted in order to understand which specific types of university differentiate the extent of knowledge-transfer activities

The dependent variables, such as numbers of patents and technology transfers in this study, are count variables (i.e. zero or positive integers). Therefore, a Poisson distribution and negative binomial distribution can be regarded as alternatives for the regression analysis here. According to the descriptive statistics in Table 1, overdispersion (i.e. the variance is much larger than the mean) is clearly identifiable. This also proved to be statistically significant from the magnitude of the alpha value. ${ }^{3}$ Consequently, a negative binomial (NB) model is more appropriate than the Poisson model in this analysis. Furthermore, in the case of domestic patents, the Vuong test result indicates that a standard negative binomial (NB) model has a better fit than a zero-inflated negative binomial (ZINB) model, while in the case of overseas patents and technology transfers, the latter has a better fit. ${ }^{4}$

Based on the above argument, a negative binomial (NB) regression model is employed for predicting the number of domestic patents. A zero-inflated negative binomial (ZINB) model is chosen for the estimation of the numbers of overseas patents and the number of technology transfers. However, the Tobit model is adopted for explaining the revenue from technology transfer, because the dependent variable (i.e. the value of revenues) can be regarded to be censored in the area of a negative real variable.

In order to prevent excessive multi-collinearity between the explanatory variables, the variables with a high VIF are excluded. ${ }^{5}$ Moreover, highly and significantly related groups of variables are employed in separate regression models. ${ }^{6}$ For example, high correlations are observed between variables of the number of papers, the number of researchers (i.e. professors and postgraduate students), and the amount of research expenditure. In particular, according to preliminary regression analysis on the relationship between independent variables, the number of researchers and the amount of research expenditure are positive and significant predictors for the number of papers. Therefore, these three groups of variables are included in different models, as shown in Tables 2 and 3 illustrating the results of the estimation.

\section{Results and Discussions}

In this section, the estimation of the regression coefficients is carried out according to different dependent variables, such as domestic patent applications (models 1-1, 1-2 and 1-3), overseas patent applications (models 2-1, 2-2 and 2-3), technology transfers (models 3-1, 3-2 and 3-3) and the revenues from technology transfers (models 4-1, 4-2 and 4$3)$.

As shown in Tables 2 and 3, the regression coefficients of the predictors for knowledge-transfer performance such as patent applications, technology transfers and the revenues from technology transfers are estimated by a standard negative binomial (NB), a zero-inflated negative binomial (ZINB) regression model and a Tobit regression model. Furthermore, considering the possibility of a heteroscedasticity problem, robust standard errors are calculated. 


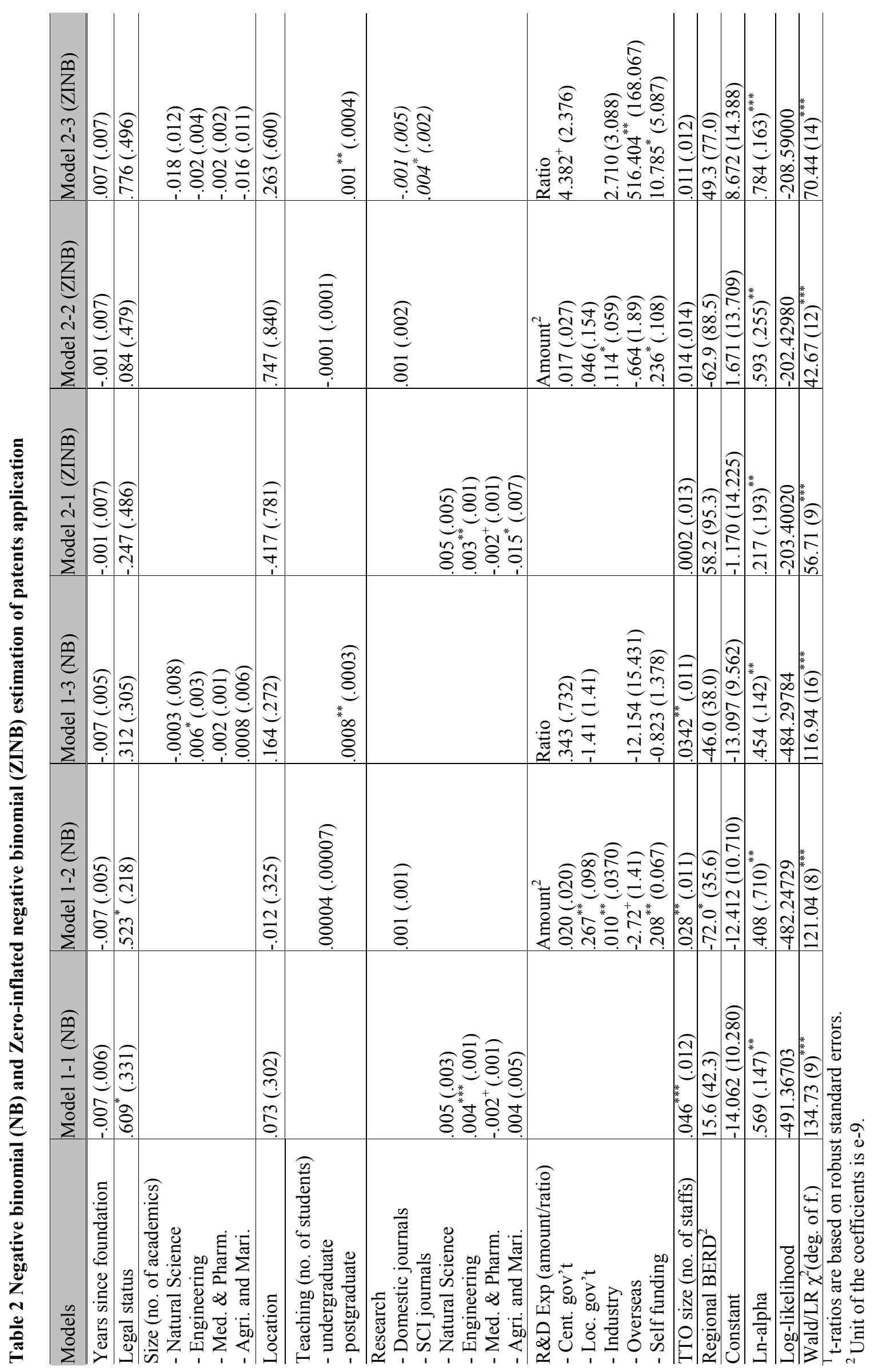




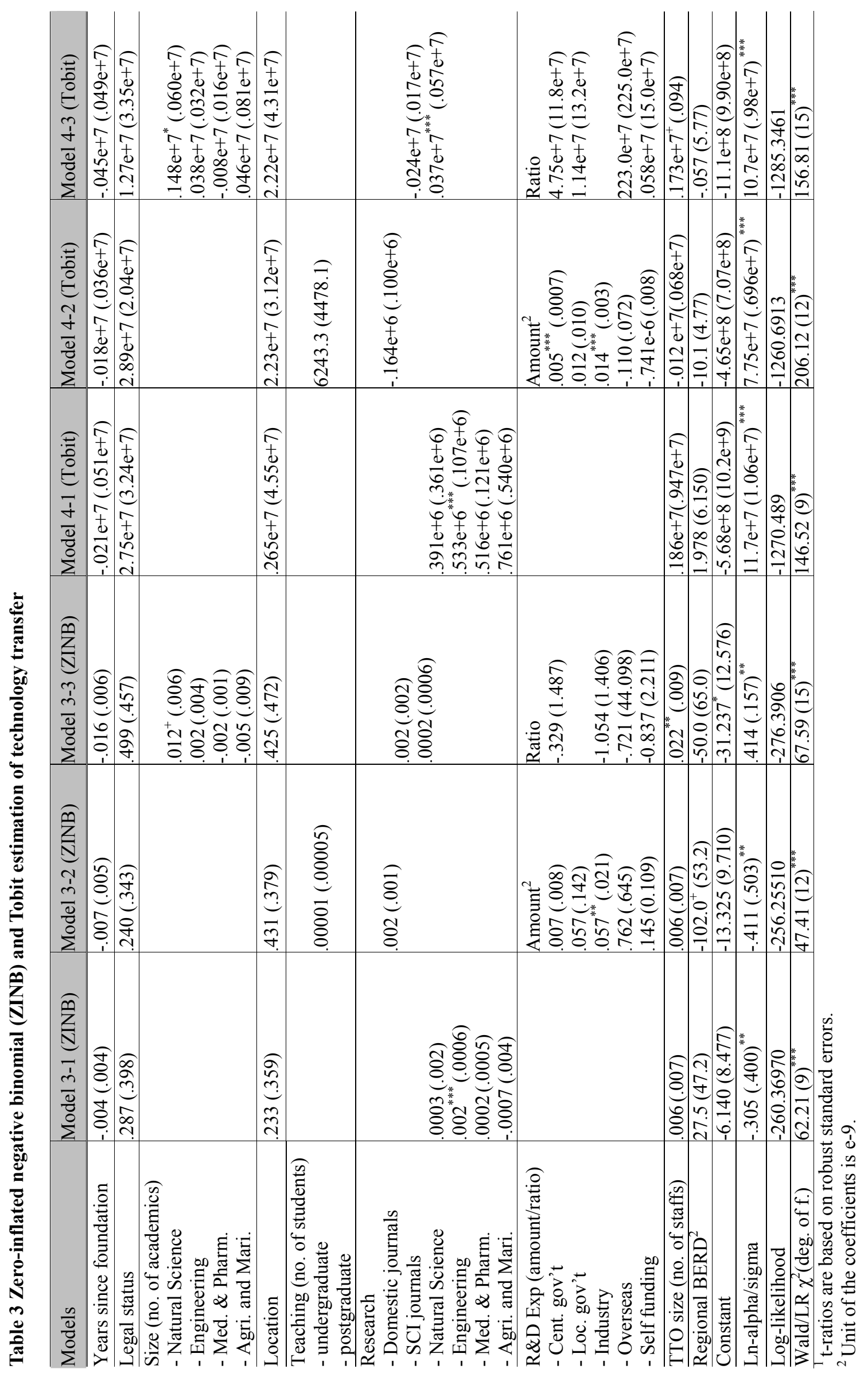


Scientific capacity as measured by the number of domestic and SCI publications is significantly related to the number of overseas patent applications and to the amount of revenue from technology transfers in models 2-3 and 4-3, while its relationship to technology transfer is not significant in models 1-3 and 3-3.

However, scientific capacity as measured by the number of papers published in different disciplines is observed to be a significant predictor for knowledge-transfer activities in all four models (i.e. models 1-1, 2-1, 3-1 and 4-1). In particular, the number of papers in engineering is strongly significant in all four models, and the number of papers in medical and pharmaceutical sciences is significant in model 1-3, which predicts domestic patent applications. In contrast, any number of papers in natural science and in agricultural and maritime science is not significant in any of the four models.

According to the results given above, Hypothesis 1 is partly supported. That is to say, on the one hand, scientific capacity as measured by SCI publications is observed to be a strong predictor for knowledge-transfer activities, whereas scientific capacity as measured by domestic publications is not. On the other hand, the significance of the relationship between scientific capacity in different disciplines and knowledge-transfer activities is supported in all four models. In particular, scientific capacity in engineering disciplines is a strong and positive predictor for knowledge-transfer activities. In conclusion, universities' scientific capacity influencing their knowledge-transfer activities is dependent on disciplinary scientific capacity (particularly in engineering) and highlevel (SCI publication) scientific capacity, rather than low-level (domestic publication) scientific capacity.

These empirical results are somewhat different from those found in developed countries' cases, such as Sapsailis et al. (2006) and Owen-Smith (2003). On the one hand, only part of the evidence supports the significant relationship of scientific capacity (as measured not by domestic publications but by SCI publications) of Korean universities to knowledge-transfer activities. On the other hand, scientific capacity in different disciplines is important for universities' knowledge-transfer activities. (The adoption of this variable contributes to the novelty of this research, compared to previous studies, which do not differentiate between the disciplines of the publications.) The latter result is reasonable in the sense that research in engineering disciplines is more closely related to industrial applications and has been more strongly supported by central government (particularly in Korea) than that in natural science disciplines. This is also reflected in the fact that Korean science has a highly specialised structure concentrating on engineering rather than pharmaceutical science, which has been strongly encouraged by the government's science and technology policy and industrial policy (Kwon, 2009b). ${ }^{7}$ The former result may imply that, as the same variable is observed to be a significant factor in Europe (Sapsailis et al. 2006) and the US (Owen-Smith 2003), scientific capacity (as measured by the number of publications in qualified journals) in all disciplines is also important for knowledge-transfer activities of universities in a rapidly industrialised country. ${ }^{8}$ However, scientific capacity as measured by domestic (unqualified or low level) publications is not strong predictor for Korean universities' knowledge-transfer activities. 
Overall, the amounts of funding from different sources are observed to be significant in all four models, whereas the proportions of those to the total amount of funding in the three models are not strongly related to the knowledge-transfer activities of the universities, except in the case of the estimation of overseas patent applications.

On the one hand, in terms of the amount of funding, funding from industry shows positive and significant relations to three of the knowledge-transfer activities. Central government funding is only significant for universities' revenues earned from technology transfer (in model 4-2), while local government funding is only significant for their domestic patenting (in model 1-2). Furthermore, overseas funding is also significant for domestic patent applications (in model 1-2). University funding is significant for domestic and overseas patenting (in models 1-2 and 2-2), but not significant for technology transfer and the revenue from this (in models 3-2 and 4-2).

On the other hand, the proportion of funding is only positive and significant for predicting overseas patent applications (in model 2-3). In particular, the proportions of central government funding, overseas funding and university funding are significant for this prediction. However, the other proportions are not significant in all three models (13, 3-3 and 4-3).

Therefore, Hypothesis $2 \mathrm{a}$ is only supported by one of the four models, which predicts revenue creation from technology transfer (model 4-2), and Hypothesis $2 b$ is supported only by model 2-3. The first result in the case of Hypothesis $2 \mathrm{a}$ is in contrast to our expectations. Therefore, we need to find another explanation of the important role of central government that we stress. This may be related to the characteristics of the funding sources. The funding from the central government has fewer requirements for commercialisation (or is less application-oriented, and longer-term) than the funding from industry. In addition, in all four models, the amount of funding from industry is more significantly and consistently related to knowledge-transfer activities than that from any other source.

Our finding on the insignificance of central government funding (regarding three out of four knowledge-transfer activities) is in the same vein as the empirical evidence of Foltz et al. (2001). Moreover, the positive and significant influence of industrial funding on knowledge-transfer activities is also found in the empirical results of Powers (2003) and Di Gregorio and Shane (2003) in the case of US universities. However, this result is contradictory to the findings of Payne and Siow (2003) and Foltz et al. (2000) in terms of the effect of central government funding, and also contradictory to Foltz et al. (2000), Foltz et al. (2001) and Powers (2004) in terms of the effect of industrial funding. In this regard, this research might be seen as merely contributing to inconsistent empirical "confusion." However, unlike previous research, the sample of this research covers all kinds of Korean universities in science and engineering. Furthermore, this empirical test has been carried out in the context of rapid catch-up country, so this result may represent the 'contextualised' relationships in such a country. That is to say, during the last decade the Korean government has invested massive funding in invigorating the commercialisation of academic research, but these efforts have not been effective in terms of Korean universities' patent applications and technology transfers (in models 1-2, 2-2 and 3-2). Even in the case of revenue creation from technology transfer (in model 4-2), the magnitude of influence of government funding is three times smaller than that of industrial funding.

Moreover, our findings show that the proportion of each source of funding to total funding failed to be observed as a significant predictor for knowledge-transfer ac- 
tivities except in model 2-3. This is in line with the empirical findings of Di Gregorio and Shane (2003), even though their dependent variable is the creation of spin-off companies. In contrast, the empirical evidence of Henderson et al. (1998) and O'Shea et al. (2005) is inconsistent with our findings, while the dependent variables of the two studies are application-oriented academic research and spin-off activities respectively. However, our dependent variables are patent applications and technology transfers. Therefore, compared with these studies, our evidence investigates a relatively unexplored area, but in a broader sense these dependent variables can be categorised together. This result may imply that the proportion of funding source has not yet become a reliable indicator for informing knowledge-transfer activities of universities in a rapid catch-up country. In spite of a lack of further evidence, we may tentatively conclude that in a rapid catchup country or in a recently industrialised Asian country, absolute size of funding does matter, but the proportion of funding does not. Another unexpected result here is that funding from universities themselves is highly related to their knowledge-transfer activities (in models 1-2 and 2-2). This may indicate that the university at an individual organisational level is exerting efforts to produce transferable knowledge to industry, and the effort is apparently effective, in spite of the need to further investigate the characteristics of the internal funding process and structure in later research.

\section{Some limitations in interpretation of the empirical findings based on our model}

Our interpretation of the empirical results has some of the typical limitations of an econometric model. First of all, the endogeniety problem (i.e. knowledge-transfer activities can encourage scientific publication and can attract research funding) has not been overcome in our model. Therefore, in this case, we need to be careful in terms of the direction of causality. In other words, we can say merely that two variables (i.e. knowledge-transfer activity and scientific capacity) are significantly and closely related to each other, if we do not accept the assumption on which the hypotheses are based. Next, our model is based on cross-sectional data; in other words, all the variables (i.e. the knowledge-transfer activities, the amount of research expenditure and the number of scientific publications) were measured in 2006. Therefore, the time lag between the point of funding and the point of patenting (due to the funding) cannot be considered in our model. Accordingly, causality is again not so clear in our discussion of the relationship between the variables in which we are interested.

\section{Conclusion}

In this paper, we have explored the relationship between the various characteristics of universities and their knowledge-transfer activities. According to the results of the descriptive statistics and the calculated correlation coefficients, institutional and environmental characteristics (legal status, years since foundation, university size, TTO size and location) with the exception of regional BERD are significantly correlated with universities' knowledge-transfer activities. Moreover, all the variables measuring the characteristics of human and financial resources, as well as teaching activity and scientific capacity, are significantly related to universities' knowledge-transfer activities. In order to investigate more closely the relationship between the various university characteristics and knowledge-transfer activities by controlling the influence of other variables, an analysis based on regression models has been carried out. 
In particular, considering the idiosyncratic characteristics of the Korean university system, as well as those of universities in other rapid catch-up countries, we are more interested in the relationship between the scientific capacity of universities and their knowledge-transfer activities, and between funding sources and knowledge-transfer activities. According to the empirical results of the regression analysis, in all four models scientific capacity in different disciplines (particularly in the field of engineering) is important for knowledge-transfer activities, while scientific capacity (regardless of the discipline) is important in only two out of eight models. This evidence is somewhat different from the results of similar research in developed countries. That is to say, scientific capacity in a specific discipline, such as engineering, is important for universities in both Western developed countries and in Korea, while scientific capacity (regardless of the discipline) is not apparently important for Korean universities, particularly in the case of domestic publication. Furthermore, this result supports the proposition suggested that strategically chosen industrial sectors in rapid catch-up countries are closely related to the scientific capacity of universities in specific disciplines. In other words, the second and third missions of universities have seemingly interacted closely.

In terms of funding sources, the amount of funding from industry is strongly related to the knowledge-transfer activities of universities, whereas the proportion of funding relative to the total amount of funding is not as significantly related to knowledge-transfer activities. These results are in the same vein as existing empirical evidence from developed countries, while the empirical results with regard to central government funding are not. In other words, our hypotheses on the importance of central government funding are not as strongly supported. In spite of this undetermined empirical evidence from developed countries, these results help us to understand the specific relationship between sources of funding and universities' knowledge-transfer activities in a rapid catch-up country. The failure to identify a significant relationship between central government funding and knowledge-transfer activities may be due to less strict requirements for commercialisation in central government R\&D programmes. Otherwise, central government funding fails to generate knowledge-transfer activities in universities. We need either more empirical and qualitative evidence to confirm these explanations, or we must put forward another, more appropriate one. In spite of this ambiguous result with regard to central government funding, industrial funding shows a more consistent significance to knowledge-transfer activities. Considering the discussion on knowledge-transfer activities in different countries, this evidence supports the proposition that, in spite of it being smaller in size than central government funding, industrial involvement has significantly stimulated the commercial activities of Korean universities.

In conclusion, we found a positive relationship between academic research and knowledge-transfer activity, which is the main focus of this paper. At the organisational level, scientific capacity (the second mission) is positively related to knowledge-transfer activities (the third mission), while undergraduate teaching (the first mission) is not significantly related to knowledge-transfer activities (the third mission). In particular, scientific capacity in engineering is the strongest predictor for knowledge-transfer activities.

Based on these findings, various policy recommendations (mainly for the Korean government) can be put forward. If the government desires programmes of university-industry collaboration (particularly aimed at the production of patents and revenuegeneration from technology transfers) to be carried out more efficiently, the size of universities, in terms of both the number of academics and their scientific performance in specific disciplines, needs to be seriously considered. Moreover, an indirect policy 
measure to attract and to increase the amount of industrial funding is very important. According to our findings, the size of TTOs is more consistently related to the number of domestic patent applications than to overseas applications for high-quality patents, technology transfers and revenue creation. This might indicate that the current TTOs are more focused on short-term (or highly and easily visible) performance than on generating more innovative and commercially meaningful outputs. Therefore, additional policy measures need to be considered in order to encourage TTOs to become more intensively involved in long-term and high value-added knowledge transfer.

\section{References}

Adams, J. and Griliches, Z. (1996). Measuring science: an exploration. Proceedings of the National Academy of Science 93, pp.12644-12670.

Adams, J. and Griliches, Z. (1998). Research Productivity in a System of Universities. Annales d'Économie et de Statistique, No. 49/50, Économie et Économétrie de l'innovation / The Economics and Econometrics of Innovation (Jan. - Jun., 1998), pp. 127-162.

Albuquerque, E. M. (2001). Scientific Infrastructure and Catching-Up Process: Notes about a Relationship Illustrated by Science and Technology Statistics. Revista Brasileira de Economia, 55 (4), pp.545-566.

Altbach, P. G. (1989). Higher Education and Scientific Development: The Promise of Newly Industrializing Countries. In Altbach et al. (eds), Scientific Development and Higher Education, New York: Praeger, pp.3-29.

Ambos, T. C., Makela, K., Birkingshaw, J. and D'Este, P. (2007). When does university research get commercialised? Institutional and individual level predictors of commercial outputs from research-council funded projects, DRUID Summer Conference 2007, Copenhagen, CBS, Denmark, 18-20 June, 2007.

Arundel, A. and Geuna, A. (2004). Proximity and the use of public science by innovative European firms. Economics of Innovation and New Technologies, 13, pp.559580.

Arundel, A., Van De Paal, G. and Soete, L. (1995). Innovation strategies of Europe's largest industrial firms. PACE report, Maastricht, University of Limbourg.

Bak, Hee-Je (2006). The Characteristics of Korean Universities' Research in terms of Structural Change: Analysis on the R\&D Expenditure after the 1980s. Conference of Korean Association of Science and Technology Studies 2006, 30 ${ }^{\text {th }}$ June, 2006.

Brooks, H. and Randazzese, L.P. (1999). University-industry relations: the next four years and beyond. In Branscomb, L.M. and Keller, J.H. (eds). Investing in Innovation: Creating an Innovation Policy that works. Cambridge: MIT Press, pp. 361399.

Carayol, N. (2007). Academic incentives, research organization and patenting at a large French university. Economics of Innovation and New Technology, 15 (2), pp.119138.

Carlsson, B. and Fridh, A. C. (2002). Technology Transfer in the United States. Journal of Evolutionary Economics, 12, pp.199-232.

Chapple, W., Lockett, A., Siegel, D. and Wright, M. (2005). Assessing the relative performance of U.K. university technology transfer offices: parametric and nonparametric evidence. Research Policy, 34 (3). pp.369-384. 
Cohen, W. M., Nelson, R. R. and Walsh, J. P. (2002). Links and impacts: The influence of public research on industrial R\&D. Management Science, 48, pp.1-23.

Coupé, T. (2003). Science is golden: academic R\&D and university patents. Journal of Technology Transfer, 28, pp.31-46.

De Campos, A. (2006). University-industry links in late-industrializing countries: a study of Unilever Brazil. DPhil Dissertation. University of Sussex, Brighton.

De Campos, A. (2009). A review of the literature on university-industry links: towards an integrated approach in the study of influencing factors. Third Conference on Micro Evidence on Innovation in Developing Economies, Institute for Applied Economic Research, Brasilia, Brazil, UNU-MERIT, United Nations University and University of Maastricht. May 10-12, 2009.

Di Gregorio, D. and Shane, S. (2003). Why do some universities generate more startups than others? Research Policy, 32, pp.209-227.

Florida, R. and Cohen, W.M. (1999). Engine or infrastructure? The university role in economic development. In Branscomb, L.M., Kodama, F., Florida, R. (eds), Industrializing Knowledge: University-Industry Linkages in Japan and the United States, London, MIT Press, pp.589-610.

Foltz, J., Barham, B. and Kim, K. (2000). Universities and agricultural biotechnology patent production. Agribusiness, 16(1), 82-95.

Foltz, J., Kim, K. and Barham, B. (2001). A Dynamic Count Data Analysis of University AgBiotech Patents. Food Marketing Policy Center Research Report, 56.

Freeman, C. and Soete, L. (1997). The economics of industrial innovation, Cambridge: The MIT Press.

Geuna, A. (1997). Allocation of Funds and Research Output: The Case of UK Universities. Revue d'Economie Industrielle, 79, pp. 143-162.

Griliches, Z. (1990). Patent statistics as economic indicators: a survey. Journal of economic literature, 28, pp. 1661-1707.

Han, K. H. (2006). Opportunities and Constraints of Patternization of Universities in Science and Engineering. Korean Journal of Sociology, 40 (1), pp. 157-182.

Hegde, D. (2005). Public and Private Universities: Unequal Sources of Regional Innovation? Economic Development Quarterly, Nov 2005; 19, pp.373 - 386.

Henderson, R., Jaffe A. B. and Manuel Trajtenberg (1998). Universities as a source of commercial technology: a detailed analysis of university patenting, 1965-1988. The Review of Economics and Statistics, 80 (1), pp.119-127.

Hwang, H. and Yoon, J. (2003). The Accumulation Process of Basic Research Capability in Korea: Case Study on ERC/SRC. Journal of Korea Technology Innovation Society, 6 (1), pp.1-19.

Hershberg, E., Nabeshima, K. and Yusuf, S. (2007). Opening the Ivory Tower to Business: University-Industry Linkages and the Development of Knowledge-Intensive Clusters in Asian Cities. World Development, 35 (6), pp.931-940.

Intarakumnerd, P. et al. (2002). National innovation system in less successful developing countries: the case of Thailand. Research Policy, 31, pp.1445-1457.

Kim, Cheol Hoi and Lee, Sang Don (2007). A study on Relationships between Performance of University-Industry Cooperations and Competency Factors of University. Journal of Korea Technology Innovation Society, 10 (4), pp.629-653.

Kwon, K.-S. (2009a). Research and Knowledge-transfer Activities of Different Types of Korean Universities. The $6^{\text {th }}$ Asialics, Hong Kong, 6-7 July 2009.

Kwon, K.-S. (2009b). The relationship between academic research and knowledge transfer activities of universities: in case of Korea. Triple Helix Conference VII, Scotland, UK, 17-19 June 2009.

20 | Journal of Contemporary Eastern Asia, Volume 10, No.1 
Lach, S. and Schankerman M. (2003). Incentives and invention in universities. CEPR, London, Discussion paper 3916.

Ljungberg, D., Johansson, M. and McKelvey, M. (2007). Does structure matter for science? The Matthew effect in the Swedish university sector. DRUID Summer Conference 2007, Copenhagen, CBS, Denmark, June 18-20, 2007.

Mansfield, E. (1998). Academic research and industrial innovation: An update of empirical findings. Research Policy, 26, pp.773-776.

Mansfield, E. (1991). Academic research and industrial innovation. Research Policy, 20, pp.1-12.

Mazzoleni, R. and Nelson, R. R. (2007). Public research institutions and economic catch-up. Research Policy, 36, pp.1512-1528.

Nelson, R.R. (1986). Institutions supporting technical advance in industry. American Economic Review, Papers \& Proceedings, 76 (2), pp.186-189.

O'Shea, R.P., Allen, T.J., Chevalier, A. and Roche, F. (2005). Entrepreneurial orientation, technology transfer and spinoff performance of U. S. universities. Research Policy, Vol. 34, pp.994-1009.

Owen-Smith, J. (2003). From separate systems to a hybrid order: accumulative advantage across public and private science at research one universities. Research Policy, 32, pp.1081-1104.

Park, K., Kwon, K.-S., Eun, J., Han, D., Han, Y. and Han, S. (2007). Analysis on the impact of university-industry collaboration policy on research activities and patenting activities in Korean universities. Korea Research Foundation.

Payne, A. A. and Siow, A (2003). Does Federal Research Funding Increase University Research Output? Advances in Economic Analysis \& Policy, 3 (1), pp.1-22.

Ponomariov, B. L. (2008). Effect of university characteristics on scientists' interaction with the private sector: an exploratory assessment. Journal of Technology Transfer, 33, pp.485-503.

Powers, J. B. (2003). Commercializing Academic Research: Resource Effects on Performance of University Technology Transfer. The Journal of Higher Education, 74 (1), pp.27-50.

Powers, J. B. (2004). R\&D Funding Sources and University Technology Transfer: What is Stimulating Universities to Be More Entrepreneurial. Research in Higher Education, 45 (1), pp.1-23.

Powers, J. B. and McDougall, P. (2005). University start-up formation and technology licensing with firms that go public: A resources based view of academic entrepreneurship. Journal of Business Venturing, 20 (3), pp.291-311.

Rosenberg, N. and Nelson, R. (1994). American universities and technical advance in industry. Research Policy, Vol. 23, pp.323-348.

Sapsalis, E., Van Looy, B., Van Pottelsberghe De La Potterie, B., Callaert, J., and Debackere, K. (2006). Antecedents of patenting activity of European universities. Working Papers CEB 05-005.RS, Université Libre de Bruxelles, Solvay Business School, Centre Emile Bernheim (CEB).

Siegel, Donald, David Waldman and Albert Link (2003). Assessing the Impact of Organizational Practices on the Relative Productivity of University Technology Transfer Offices: An Exploratory Study. Research Policy. 32 (1), pp.27-48.

Sine, W., Shane, S. and Di Gregorio, D. (2003). The halo effect and university technology licensing. Management Science. 49 (4), pp.478-497.

Sohn, B., Lee, B. and Jang, J. (2006). Current situation and prospect of Korean university-industry cooperation. Venture Creation Study, 1 (1), pp.31-32. 
Sohn, D.-W. and Kenney, M. (2007). Universities, Clusters, and Innovation Systems: The Case of Seoul, Korea. World Development, 35 (6), pp.991-1004.

Song, Sung-Soo (2002). A study on the Characteristics of Science and Technology Policy in Korea. Korean Journal of Study of Science and Technology, 2 (1), pp.63-83.

Thursby, Jerry and S. Kemp (2002). Growth and Productive Efficiency of University Intellectual Property Licensing. Research Policy, 31 (1), 109-124.

Varga, A. (1998). University Research and Regional Innovation. Dordrecht: Kluwer Academic Publishers.

Von Tunzelmann, G. N. (1995). Technology and industrial progress: the foundations of economic growth. Cheltenham: Edward Elgar.

Wong, P.-K., Ho, Y.-P. and Singh, A. (2007). Towards an "Entrepreneurial University" Model to Support Knowledge-Based Economic Development: The Case of the National University of Singapore. World Development, 35 (6), pp.941-958.

Eun, J-.H., Lee, $\mathrm{K}$ and $\mathrm{Wu}, \mathrm{G}$. (2006). Explaining the "University-run enterprise" in China: A theoretical framework for university-industry relationship in developing countries and its application to China. Research Policy, 35, pp.1329-1346.

MEST (2008). National Project towards Building: World Class Universities 2008 2012, Korean Ministries of Education, Science and Technology.

Lee, J.S. (2009). Korea's science \& technology policy. In: Paper Presented at the AAAS Annual Conference, Chicago, IL.

Seung, J. and Kim, W. (2010), Post Catch-Up Innovation and Development of Creative Talent in Korea: Limitations and Challenges, STI Policy Review, 1(3), pp.39-51.

Horta, H. (2010), The Role of the State in the Internationalization of Universities in Catching-up Countries: An Analysis of the Portuguese Higher Education System, Higher Education Policy, 23, pp.63-81.

Song, W. and Hwang, H-.R. (2006) The Technological Innovation Patterns of Component Suppliers in the Post Catching-up Period: The Case Study of Component Suppliers in Mobile Phone Industry, Journal of Korea Technology Innovation Society, 9(3), pp. 435-450. 


\section{Notes}

1 In this paper, 'knowledge-transfer activities' can be defined as academics' various efforts to disseminate academic knowledge through various means such as patenting, licensing and the creation of spin-offs.

${ }^{2}$ In this paper, we define 'universities engaged in science and engineering' as universities with at least one department of science and engineering, because the research analysis is based on the organisational level.

3 All the alpha values in NB and ZINB models introduced here are significantly different from zero at the level of $95 \%$ confidence.

${ }^{4}$ In case of the estimation of domestic patents in models 1-1, 1-2, and 1-3, Vuong test results of zero-inflated vs. standard negative binomial consistently support the latter (i.e. all three z-values resulted from the tests are smaller than 1.96). However, Vuong test results in models 2-1, 2-2, 2-3, 3-1, 3-2 and 3-3 support ZINB models, which means that the dependent variables in these models have excessive zeros.

${ }^{5}$ In each model, we exclude several independent variables with larger than 10 VIF (Variance Inflation Factor) value, because those variables are possibly linearly related to other independent variables. In this case, exclusion of significant independent variables could result in the overestimation of the significance of remaining independent variables. However, because the three groups of variables are highly and significantly correlated, such possibility can be minimised.

${ }^{6}$ In order to prevent high VIF value, the baselines of models cannot be maintained consistently. For example, in model 1-3 the baseline of the five variables measuring proportion of the funding sources with regard to total funding is the proportion of industrial funding, while in model 2-3 the baseline is the proportion of local government funding.

${ }^{7}$ Not only disciplines of scientific capacity but also the discipline of industry is important in relation to the knowledge-transfer activities of universities. In terms of specific traditional sectors such as chemical and electrical engineering, historical evidence shows that the university-industry linkage is very close (Freeman and Soete, 1997; Von Tunzelmann, 1995; Rosenberg and Nelson, 1994). Recent empirical studies show that certain industrial sectors are more closely related to universities' knowledge-transfer activities. These include utilities and aerospace (Arundel and Geuna, 2004), TV/radio, communication, drugs and oil (Cohen et al., 2002), and pharmaceutical, aerospace and food (Arundel et al., 1995). In particular, according to Arundel and Geuna (2004), the sectors of firms evaluating public research as important sources of knowledge vary from region to region (i.e. Europe, other Europe, North America and Japan). This means that we need to consider the industrial structure of the particular country where the university and industry are located.

8 The same result is reported by Kim and Lee (2007)'s study on Korean universities' knowledge-transfer activities, even though the estimation is carried out based on the OLS (Ordinary Least Square) model and the sample size $(\mathrm{N}=60)$ is smaller than ours. 